\title{
Latest Advances in Alternative Cementations Binders than Portland cement
}

\author{
Mr.Priji E Moses ${ }^{1}$, Dr Bhagavathi Perumal ${ }^{2}$ \\ ${ }^{I}$ Research Scholar, Bharath University, Chennai \\ ${ }^{2}$ Professor, RMK College of Engineering and Technology, Chennai
}

\begin{abstract}
There is a burgeoning interest in the development, characterization, and implementation of alternatives to Portland cement as a binder in concrete. The construction materials industry is under increasing pressure to reduce the energy used in production of Portland cement clinker and the associated greenhouse gas emissions. Further, Portland cement is not the ideal binder for all construction applications, as it suffers from durability problems in particularly aggressive environments. Several alternative binders have been available for almost as long as Portland cement, yet have not been extensively used, and new ones are being developed. In this paper, four promising binders available as alternatives to Portland cement are discussed, namely calcium aluminate cement, calcium sulfoaluminate cement, alkali-activated binders, and supersulfated cements. The history of the binders, their compositions and reaction mechanisms, benefits and drawbacks, unanswered questions, and primary challenges are described.
\end{abstract}

Keywords

A. Hydration;

D. Alkali-activated cement;

D. Calcium aluminate cement;

D. Sulfoaluminate;

D. Granulated blast furnace slag

\section{Motivation}

Since the development of Portland cement over 175 years ago, it has become the dominant binder used in concrete for construction. Annual worldwide Portland cement production is approaching $3 \mathrm{Gt}$ [1]. Praised for its versatility, durability, and economic value, Portland cement concrete is receiving increasing recognition for its relatively low embodied energy compared to other building materials, as shown in Fig. 1[2], and for its use of local materials, thereby reducing energy and pollution costs associated with material transport.

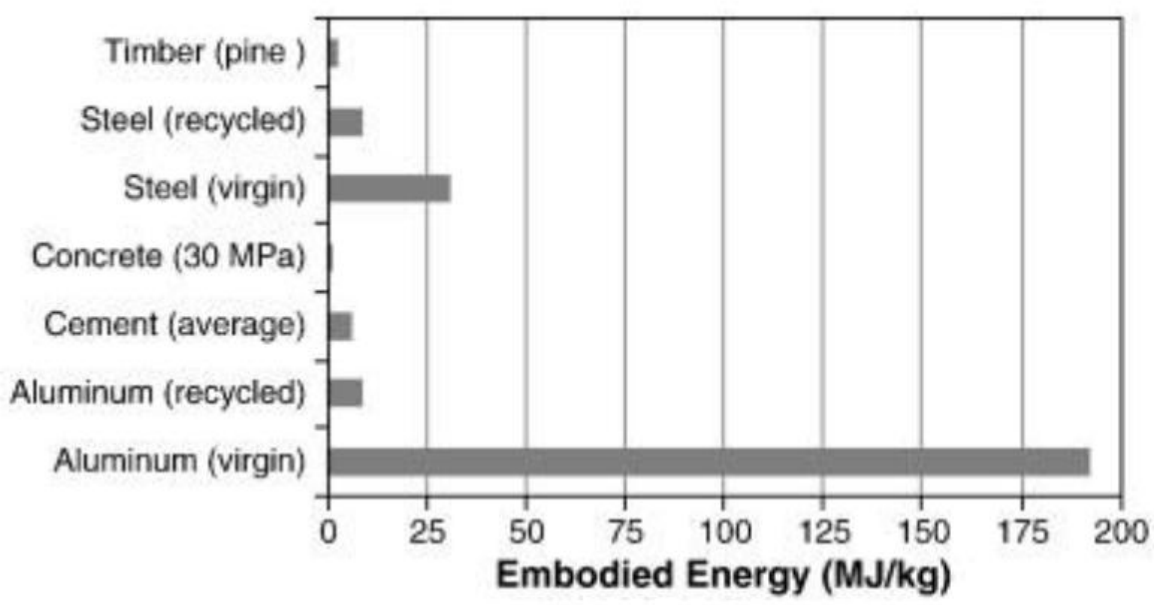

Fig. 1.

Embodied energy of common building materials [2]

However, Portland cement is not without problems. Because such vast quantities are produced, manufacturing of Portland cement consumes 10-11 EJ of energy annually, approximately 2-3\% of global primary energy use. Furthermore, Portland cement production results in approximately $0.87 \mathrm{t}$ of carbon dioxide for every tone of cement produced [3]; this accounts for 5\% of manmade $\mathrm{CO} 2$ emissions [3]. The cement 
industry is under pressure to reduce both energy use and greenhouse gas emissions and is actively seeking alternatives to this familiar and reliable material.

Coupled with the interest in seeking low-energy, low-CO2 binders is an interest in finding re-use for waste materials from other industries. Portland cement concrete already accommodates a wide variety of waste materials used as supplementary cementing materials, including fly ash from coal combustion, ground granulated blast furnace slag from iron production, and silica fume from ferrosilicon production. However, these are used to replace only a portion of the cement in concrete, typically on the order of 10-50\% (although sometimes used in greater quantities). There is interest in pushing this envelope further, to create binders made entirely or almost entirely from waste materials. Additional motivation for exploring alternatives to Portland cement can be derived from its shortcomings in certain applications and environments. For instance, rapid-repair applications demand a faster strength gain than Portland cement concrete can provide. Similarly, environmental conditions with high acidity or high sulfate concentrations can cause substantial degradation of Portland cement concrete. For such cases, there is a demand for 000055E0 Portland cement alternatives. New binders are being developed for concrete that promise to reduce the environmental impact of construction, use a greater proportion of waste materials, and/or improve concrete performance. These materials represent a substantial departure from the traditional chemistry of Portland cement, and therefore do not benefit directly from the many years of research into its reaction mechanisms, property development and durability. Furthermore, new materials have difficulty finding acceptance in the construction industry, making implementation challenging. In this paper we discuss some of the alternative binders which are attracting increasing attention in research and practice, summarizing the current understanding, gaps in knowledge and challenges. This paper does not address all of the possible Portland cement alternatives that are being developed, studied, and used. Rather, we have chosen four materials that show particular promise as Portland cement alternatives: calcium aluminate cement, calcium sulfoaluminate cement, alkali-activated binders, and supersulfated cement. The challenges facing new concrete binders are twofold. Primarily, there are many fundamental questions to be addressed with respect to processing, chemical and physical behavior, and performance. Secondly, after a strong basic understanding of the material is in place, it is important to establish standard composition and/or performance parameters for the materials and to incorporate them into building codes and specifications. In this paper the challenges of standardization and specifications are addressed jointly in the next section, and we then proceed to discuss the scientific challenges unique to each binder separately.

\section{Specifying alternative binders}

Specifications for building materials can generally be classified as either prescriptive or performancebased. Certainly, a prescriptive specification for Portland cement would preclude the use of an alternative binder. A performance-based specification, however, may provide sufficient flexibility to allow the use of a non-Portland cement binder. There are differing degrees of prescription in cement standards and specifications in place worldwide. In the United States, ASTM has parallel prescriptive (ASTM C150 [4]) and performancebased (ASTM C1157 [5]) standards for cement, but the acceptance of ASTM C1157 is not yet widespread among state regulatory authorities. ASTM C 1600 [6] has recently been adopted and covers the broader category of rapid-hardening hydraulic cements in a performance-based approach. In the European Union, EN 197-1 [7] is a predominantly prescriptive cement standard which is referenced by the concrete standard EN 206-1 [8], and this would appear to place some restrictions on the use of non-Portland cements in that region, unless productspecific Technical Approvals can be obtained. Each EU nation also has its own set of national appendices which sit beneath the EU Standards, and some of these are more permissive than others in terms of the scope for introducing alternative binder chemistries. Other nations including Canada and Australia have good scope for acceptance of materials on a performance basis within existing legislative frameworks. There also exists in Ukraine a highly developed framework of prescriptive standards governing specific classes and formulations of non-Portland cements, which have been generated through 50 years of development of alkali activation technology. International developments in standards for non-Portland cements are being driven and monitored by RILEM Technical Committee 224-AAM. This committee has a specific focus on alkali-activated binders, but the availability of performance-based standards is motivated by the desire to use performance rather than chemistry as the primary criterion for acceptance of a binder type, since composition-based criteria are necessarily binder-specific. The focus of the RILEM Committee does not specifically limit the applicability of its outcomes to alkali-activated materials. Probably the most daunting challenge facing developers of performance-based standards is exactly how a testing regime may be designed which is sufficiently inclusive to enable its use to test and validate a wide range of binder systems, but which is also restrictive enough to ensure good performance of materials when they are mixed and placed under less-controlled real-world conditions. The selection of curing conditions (for example, whether lime-water curing is useful for non-Portland cement systems), whether the most critical tests are conducted on precursors, pastes, mortars or concretes, and the need to transfer as much as possible of knowledge from Portland cement and concrete technology to the new binder 
systems, are all essential areas which require input from both the commercial and research sectors if satisfactory outcomes are to be achieved.

\subsection{Calcium aluminate cements}

\section{Alternative binders}

Calcium aluminate cements (CACs) are a specialty class of cements containing primarily monocalcium aluminate (CA) and sometimes C12A7 and/or CA2. Silica may be present in small amounts in the form of C2S and/or C2AS (gehlenite). Small amounts of ferrite may also be present in the form of a C4AF solid solution with variable A/F ratio [9]. Originally developed in the early 1900s, near La Teil, France by Jules Bied of the J. \& A. Pavin de Lafarge company, CACs were invented to resist sulfate attack [9]. Calcium aluminate cement concrete has several distinct advantages over traditional Portland cement concrete, including rapid strength gain upon setting and enhanced resistance to abrasion, sulfate attack and alkali-silica reaction. Furthermore, production of CAC results in lower $\mathrm{CO} 2$ emissions than Portland cement production. Currently, CACs are mainly used in refractory and building chemistry applications, such as floor screeds and rapid-hardening mortars [9]. However, CACs are gaining renewed interest in the construction industry due to their rapid hardening and enhanced durability properties compared to other cementitious binders.

Despite the fact that CAC was developed over 100 years ago and has many advantageous characteristics, it is not used as extensively as Portland cement. Widespread use of CAC is limited by two primary challenges. First, a process called "conversion" occurs in hydrated CAC over time, whereby metastable hydrates convert to stable hydrates, leading to an increase in porosity and subsequent decrease in strength. Several building collapses in the 1970s were initially attributed to CAC conversion, and many structural codes subsequently banned use of the material. Later investigations revealed that in one of the collapses, improper structural detailing was to blame, and other failures were a result of improper material usage despite manufacturer recommendations. Since this time, intensive research has provided a greater understanding of CAC chemistry and behavior. A report by the Concrete Society in 1997 provided improved guidance for predicting long-term properties, and, as a result, the technical concrete market has seen resurgence in interest and use of this alternative cementitious binder [10]. Secondly, CAC is expensive compared to Portland cement, with the cost related directly to the limited supply of bauxite, the main source of alumina in CAC production. Both of these challenges need resolution if this material is to gain acceptance as a viable Portland cement alternative.

\subsubsection{Hydration and property development}

In Portland cement the temperature history affects primarily the rate of reaction, whereas in CAC the temperature during hydration also impacts the phases that form and the rate of transition from metastable to stable hydrates (i.e. the conversion process). At low curing temperatures, metastable hydrates CAH10 and $\mathrm{C} 2 \mathrm{AH} 8$ form. It is generally accepted that the predominant metastable hydrate formed at temperatures below $15{ }^{\circ} \mathrm{C}$ is $\mathrm{CAH} 10[11]$. As the curing temperature increases to $30{ }^{\circ} \mathrm{C}, \mathrm{C} 2 \mathrm{AH} 8$ is also formed; however, the formation of CAH10 is not thermodynamically favored and formation of $\mathrm{C} 2 \mathrm{AH} 8$ is slow as temperatures approach $30{ }^{\circ} \mathrm{C}$ [12] and [13]. The conversion of these hydrates to the stable C3AH6 phase is accompanied by the formation of AH3 gel and the release of water. This is a thermodynamically inevitable process. As a result of the conversion process, the paste increases in porosity and subsequently the strength of the material decreases. At higher curing temperatures $\left(>70{ }^{\circ} \mathrm{C}\right)$ the stable hydrate C3AH6 is predominantly formed [9]. Fig. 2 shows a schematic of the conversion process and approximate temperature ranges for the formation of metastable and stable hydrates.

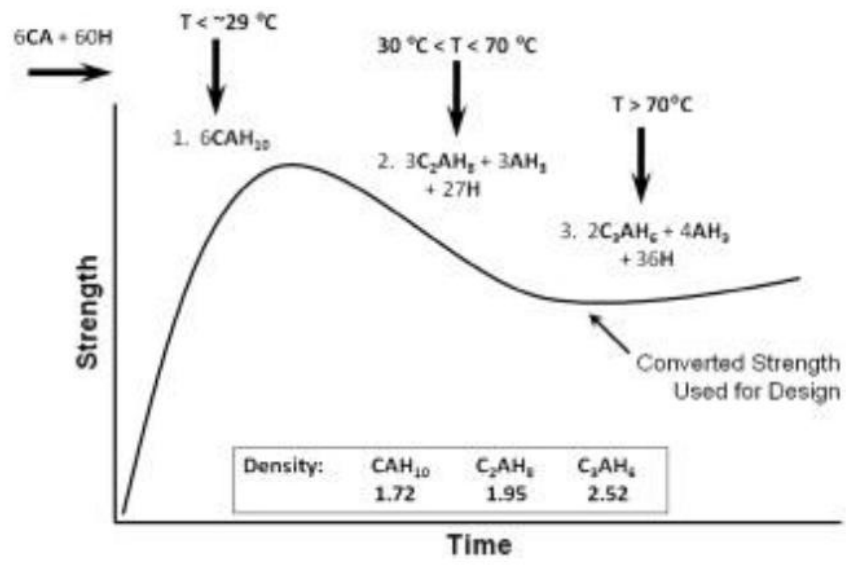

Fig. 2. 
Schematic of conversion implies densification of hydrates which leads to increased porosity and strength reduction.

While the conversion process may take years in the field, it can be simulated in the laboratory by curing at $38{ }^{\circ} \mathrm{C}$ immediately after casting. This leads to an accelerated formation of the stable hydrates, and the subsequent minimum in strength is typically realized within 5 days [10]. Fig. 3 shows scanning electron microscope images of CAC microconcretes cured isothermally at $20^{\circ} \mathrm{C}$ and $38{ }^{\circ} \mathrm{C}$, promoting the formation of metastable (higher strength) and stable (lower strength) hydration products, respectively. In Fig. 3a, despite the large amount of unreacted CA present, the microstructure is relatively dense, filled with hydration product (CAH10) and discrete porosity similar to a traditional high-performance Portland cement microstructure. In sharp contrast, in Fig. 3b there is little unreacted CA. Additionally, the porosity that exists is evident throughout the entire microstructure, resulting in a lower strength material for $38{ }^{\circ} \mathrm{C}$ isothermal curing than for $20{ }^{\circ} \mathrm{C}$ isothermal curing.

a)

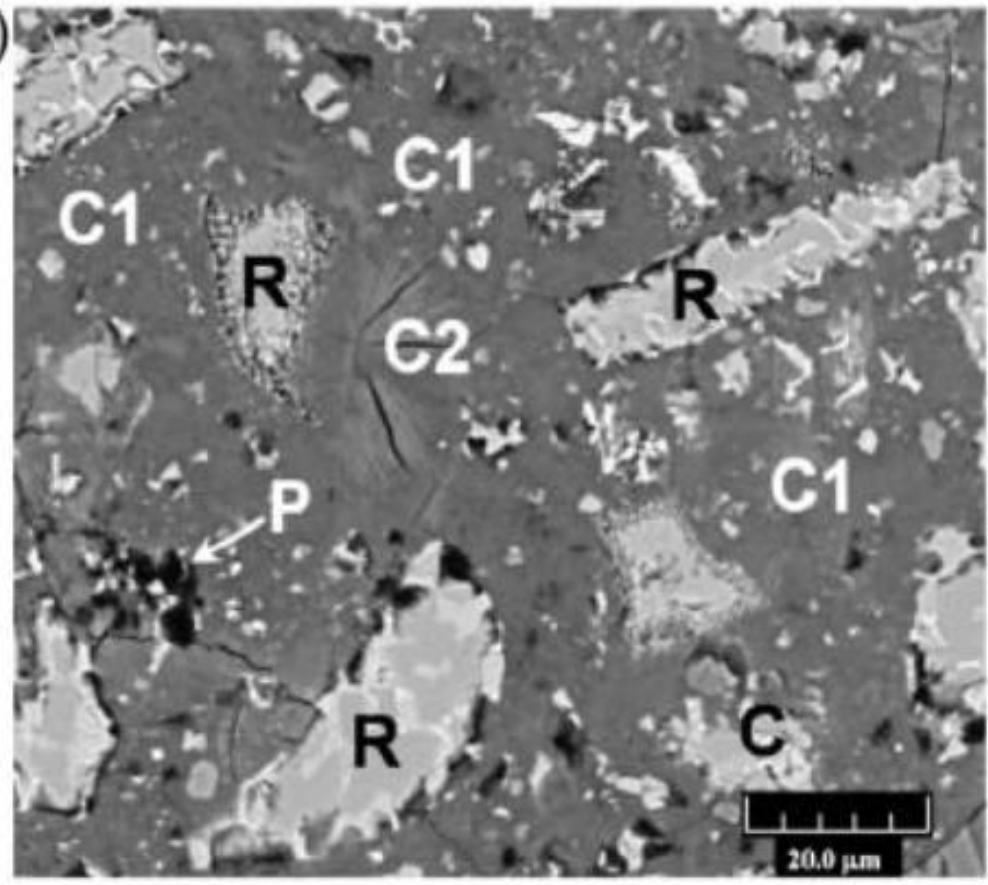

b)

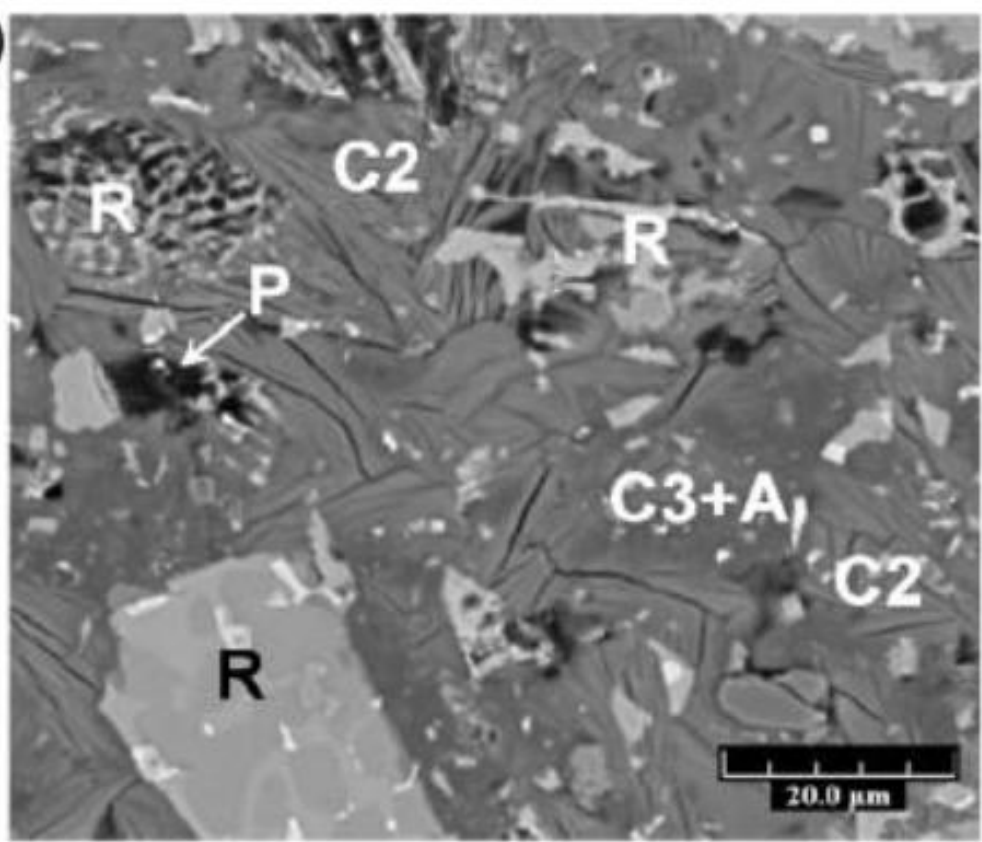

Fig. 3. 
SEM images of CAC microconcrete: a. unconverted, high strength; b. complete conversion, lower strength, increased porosity (both scale bars $=20 \square \mathrm{m}$ ). $\mathrm{C}=$ unreacted $\mathrm{CA}, \mathrm{A}=\mathrm{AH} 3 \mathrm{gel}, \mathrm{C1}=\mathrm{CAH10}, \mathrm{C} 2$ $=\mathrm{C} 2 \mathrm{AH8}, \mathrm{C3}=\mathrm{C} 3 \mathrm{AH} 6, \mathrm{R}=$ partially reacted $\mathrm{CA}$ grain, $\mathrm{P}=$ pore.

It is recognized that conversion is an inevitable process and research has shown that the best approach when using CAC concrete is to design for the lower, converted strength rather than for the maximum strength, thereby eliminating long-term problems post-conversion [10]. Recent research in CAC systems has focused less on strength development, but instead on characterizing and predicting dimensional stability in order to reliably predict field performance, as well as blending the cement with supplementary cementing materials in order to reduce the cost of concrete made from CAC.

Recent research efforts investigating calcium aluminate cements were highlighted in the 2008 Centenary Conference [14]. The proceedings include information specific to hydration, increased understanding of mechanical and volumetric properties, durability, refractory and building chemistry applications, and the use of fillers and reactive powders in conjunction with CACs.

Early-age microstructural development was investigated by Pöllmann et al. [15] using cryo-scanning electron microscopy (SEM) coupled with heat-flow calorimetry and in situ X-ray diffraction. Combining these techniques they were able to observe the transformation of AH3 gel to crystalline AH3 phases at early ages (up to $8 \mathrm{~h}$ after mixing). From 8 to $15 \mathrm{~h}$, cryo-SEM showed an increasing density of CAH10 and the crystallization of layered, hexagonal crystals of C2AH8.

Ideker et al. [16] and [17] demonstrated the profound effect of curing temperature on early-age volume changes. Specifically, under isothermal curing, the formation of metastable hydrates (primarily CAH10) was linked to shrinkage. Conversely, formation of stable phases (especially C3AH6) was linked to expansion of the material. The mechanisms governing these volume changes are not obvious. Simple volume change calculations of the hydrates for conversion from CAH10 to C2AH8 or CAH10 to C3AH6 show volume increases of 4.4 and $2.4 \%$, respectively. This includes the release of water from CAH10 (if this is not done, an incorrect net shrinkage is calculated). The researchers have conjectured that the ability of the system to accommodate water release and subsequent water movement within the pore structure could be linked to expansion as a result of increased hydraulic pressure [16] and [17].

Lamberet et al. [18] and Alexander et al. [19] highlighted the improved performance of CAC in sewer tunnel linings compared to OPC. The presence of higher concentrations of aluminum ions in CAC systems combined with low $\mathrm{pH}$ levels prevalent in wastewater conveyance were shown to inhibit bacterial growth, thereby reducing damage in CAC-based mortar linings.

The reaction kinetics and long-term properties of Portland cement-dominated and calcium aluminate cement-dominated self-leveling flooring mortars were investigated by Kighelman et al. [20]. They found that CAC-dominated systems were more stable volumetrically due to early-age strength gain and a denser microstructural formation. They also found that the CAC-dominated systems showed improved abrasion resistance compared to OPC-dominated systems.

Gosselin [21] found that the incorporation of SCMs, in particular ground granulated blast furnace slag (GGBFS) and silica fume, created more space and available water for the hydration of CA. At early ages this resulted in further hydration of CA in these systems compared to pure CAC systems. Reactivity of SCMs was not observed until later ages ( $>1$ day), similar to Portland cement systems, and as a result the incorporation of SCMs did not significantly enhance early-age strength gain. In field applications of CACs, an accelerator (typically Li2SO4-based) is commonly used to regulate setting time. In pure CAC systems Gosselin found that an accelerator actually reduced hydration of CA at early ages and decreased strength gain due to an increase in the formation of denser stable hydrates (C3AH6 and AH3) at early ages. This finding has implications on the use of CAC in field applications, as it seems that the problem of strength loss associated with conversion may be partially mitigated through the use of SCMs and/or chemical accelerators. Little work has been done on modeling the reaction kinetics of CAC, as research has generally focused on developing predictable mechanical behavior and gaining a better understanding of the formation of metastable and stable hydrates. More detailed investigations of hydration kinetics will be welcomed in the future and will further enhance our understanding of calcium aluminate cement systems and how to utilize them through avoidance of or proper characterization of conversion.

\subsection{Calcium sulfoaluminate cements}

Calcium sulfoaluminate (CSA) cements contain ye'elimite (C4A3S) as a major constituent (30-70\%). Ye'elimite was introduced as a cementitious phase in the 1960s, when it was patented by Alexander Klein as an expansive or shrinkage compensating addition to cementitious binders ("Klein's compound") [22]. While CSA cements are not widely used in Europe and the U.S., they have been produced, used and standardized in China for about 30 years [23], [24], [25], where they are known as the "third cement series." Two types of clinkers are defined, sulfoaluminate belite clinker (containing mainly (C4A3S) and $\mathrm{C} 2 \mathrm{~S}$ ) and ferrialuminate clinker 
(containing mainly (C4A3S), C4AF and $\mathrm{C} 2 \mathrm{~S}$ ). The clinkers are interground with different levels of calcium sulfate in order to obtain rapid-hardening, high strength, expansive, or self-stressing cements. CSA cements have been used in China as a binder for concrete in bridges, leakage and seepage prevention projects, concrete pipes, precast concrete (e.g. beams and columns), prestressed concrete elements, waterproof layers, glass fiber reinforced cement products, low temperature construction and shotcrete [23], [24],. In addition, due to their low $\mathrm{pH}$, their low porosity and the ability of ettringite and AFm phases to bind heavy metals, calcium sulfoaluminate cements and their blends with Portland cement are of interest in the field of hazardous waste encapsulation .

CSA cements are receiving increasing attention because they promise to provide a low-CO2 alternative to Portland cement. Compared to alite, which releases $0.578 \mathrm{~g} \mathrm{CO} 2$ per $\mathrm{g}$ of the cementing phase when made from calcite and silica, calcium sulfoaluminate clinker releases only $0.216 \mathrm{~g} \mathrm{CO} 2$ per g of cementing phase when made from limestone, alumina and anhydrite. The firing temperature used to produce CSA clinker is typically $1250{ }^{\circ} \mathrm{C}$, about $200^{\circ} \mathrm{C}$ lower than that used for Portland cement clinker. In addition, this type of clinker is easier to grind than Portland cement clinker [23].

\subsubsection{Raw materials and binder composition}

CSA clinker can be produced from limestone, bauxite (iron-rich bauxite in the case of ferrialuminate clinker) and calcium sulfate (anhydrite or gypsum) [23], [24], [25],. The high cost of bauxite presents an economic challenge for CSA cements, just as for CAC. Therefore, a significant amount of effort has been put into exploring industrial by-products or waste materials such as fly ash, blast furnace slag, phosphogypsum, baghouse dust or scrubber sludge for the manufacture of calcium sulfoaluminate-based clinkers . Generally, the same production process as for Portland cement clinker, either in shaft or in rotary kilns, can be applied using a clinkering temperature between 1250 and $1350{ }^{\circ} \mathrm{C}$.

Depending on the raw meal composition, CSA clinkers can contain various other hydraulic phases such as belite, calcium aluminoferrite, excess anhydrite or free lime, calcium aluminates, perovskite or gehlenite [24],. The latter two phases can be regarded as hydraulically inactive. To increase the reactivity of the belite phase, which is responsible for late strength development of sulfoaluminate belite cements, minor ingredients can be added to the raw meal.

Usually about $15-25$ wt.\% of gypsum is interground with the clinker for optimum setting time, strength development and volume stability. Depending on the level of calcium sulfate addition, CSA cements with different properties can be obtained. CSA cements can also be used in blends with other cementitious materials including Portland cement, burnt oil shale or limestone, to improve their strength development or to formulate rapid setting/hardening binder systems.

\subsubsection{Hydration}

The kinetics of pure ye'elimite hydration and product development are influenced by the addition of calcium sulfate or calcium hydroxide. With water alone, (C4A3S) reacts with water according to Eq. (1) to form monosulfate and aluminum hydroxide, with the latter being usually X-ray amorphous. The kinetics of this reaction are quite slow, exhibiting a dormant period of several hours. The addition of gypsum or anhydrite accelerates the hydration kinetics, and ettringite is formed according to Eq. (2), together with aluminum hydroxide, instead of monosulfate. When the calcium sulfate is consumed, monosulfate is formed according to Eq. (1). The ratio between ye'elimite and calcium sulfate determines the ratio between ettringite and monosulfate in the final product. Above a calcium sulfate to ye'elimite molar ratio of 2, only the reaction according to Eq. (2) occurs. With the addition of calcium hydroxide, ye'elimite reacts very rapidly to form C4AHx, whereas the combined addition of calcium hydroxide and calcium sulfate leads to the rapid formation of ettringite according to Eq. (3).

In CSA cements, which generally contain several hydraulic phases, similar reactions take place [23], [24],. Usually the (C4A3S) is more reactive than the other accessory phases like C2S, C4AF or CA. Depending on clinker composition, additional hydration products such as strätlingite (C2ASH8) (Eq. (4)), calcium silicate hydrates or CAH10 may form. Fig. 4 shows the phase development of a calcium sulfoaluminate cement containing belite with ongoing hydration, derived by thermodynamic modeling [58]. The water-to-cement ratio needed for complete hydration is determined by the amount of calcium sulfate added, and is at a maximum around an addition of $30 \%$ calcium sulfate [23] . This is higher compared to Portland cement, e.g. 0.78 for pure ye'elimite reacting with 2 molar equivalents of anhydrite, or around 0.60 for technical cements [23]. In comparison to Portland cement, cements based on calcium sulfoaluminate react faster, and most of the hydration heat evolution occurs between 2 and $24 \mathrm{~h}$ of hydration. Typical values for heat of hydration are close to $400 \mathrm{~J} / \mathrm{g}$ cement after $72 \mathrm{~h}$ by conduction calorimetry.

\section{Equation(1) \\ $\mathrm{C}^{4} \mathrm{A3S}^{-}+18 \mathrm{H} \square \mathrm{C} 3 \mathrm{~A} \cdot \mathrm{CS}^{-} \cdot 12 \mathrm{H}+2 \mathrm{AH} 3$}


Equation(2)

$$
\begin{aligned}
& \mathrm{C} 4 A 3 S^{-}+2 \mathrm{CS}^{-} \mathrm{H} 2+34 \mathrm{H} \square \mathrm{C}^{-} \mathrm{A} \cdot 3 \mathrm{CS}^{-} \cdot 32 \mathrm{H}+2 \mathrm{AH} 3 \mathrm{Equation}(3) \\
& \mathrm{C} 4 \mathrm{A3S} \mathrm{CS}^{-}+\mathrm{CS}^{-}+6 \mathrm{CH}+74 \mathrm{H} \square 3 \mathrm{C} 3 \mathrm{~A} \cdot 3 \mathrm{CS}^{-} \cdot 32 \mathrm{H} 1
\end{aligned}
$$

\section{Equation(4)}

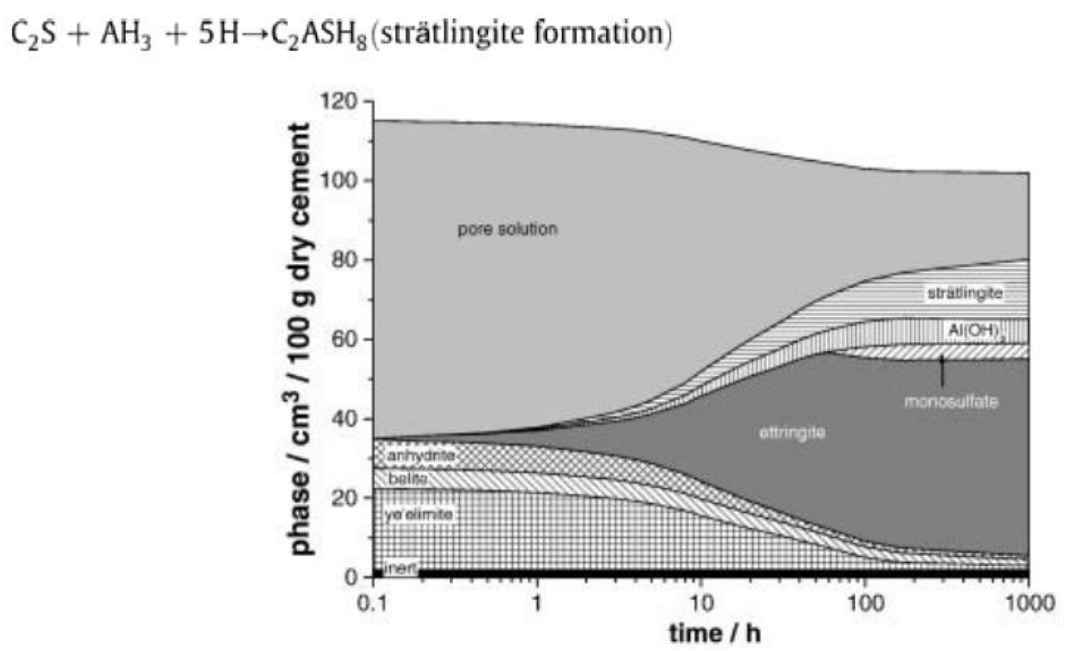

Fig. 4.

\section{Phase development of a CSA cement (water/cement $=0.80$ ) as a function of hydration time calculated by thermodynamic modeling.}

The liquid phase is dominated at an early age by $\mathrm{Na}, \mathrm{K}, \mathrm{Ca}, \mathrm{Al}$ and sulfate, until the added calcium sulfate has been consumed. The $\mathrm{pH}$ value in this period is between 10 and 11. After consumption of the calcium sulfate, a strong decrease of calcium and sulfate concentrations and an increase of $\mathrm{pH}$ to about 12.5 occur. During the first hours of hydration, silicate concentrations in the pore solutions are lower than for OPC, wheras after several days they are comparable in both systems. Microstructural investigations [24], [27], Fig. 5, have revealed mainly the presence of space-filling ettringite needles, together with monosulfate, aluminum hydroxide, and calcium silicate hydrates and/or strätlingite, leading to a very dense, low porosity microstructure. Fig. 5. Scanning electron micrographs (backscattered electron images of polished sections) of hydrated CSA cement after a) $16 \mathrm{~h}$ and b) $28 \mathrm{~d} \mathrm{C}=\mathrm{CSA}$ clinker, $\mathrm{G}=$ gypsum, $\mathrm{E}=$ ettringite, $\mathrm{Gel}=$ gel-like $\mathrm{Al}(\mathrm{OH}) 3$ and $\mathrm{S}=$ strätlingite

\subsubsection{Properties}

The setting times of CSA cements depends on their ye'elimite content, the kind and content of minor phases, and the amount and reactivity of the added calcium sulfate. Typical values are between $30 \mathrm{~min}$ and $4 \mathrm{~h}$ [23]. Compared to Portland cement, CSA cements in general reach higher early and late strengths [23].

CSA cements exhibit a chemical shrinkage, which is related to the fact that the apparent density of the water bound in the hydrated phases, such as ettringite, is higher than the density of free water. It can be calculated through thermodynamic modeling that CSA cements should have a theoretical chemical shrinkage of about $11 \mathrm{~cm} 3 / \mathrm{g}$ cement after 28 days, whereas a Portland cement reaches about $4-5 \mathrm{~cm} 3 / \mathrm{g}$. Chemical shrinkage of CSA cement was experimentally found to be of the same order of magnitude as the predicted value. It should also be noted that expansion may occur if ettringite forms in reasonable amounts after setting, which can be triggered by the amount of added calcium sulfate. Calcium oxide and calcium hydroxide accelerate ettringite formation, and so can also lead to expansion Further, due to the high water/cement ratio needed for complete hydration, which is typically around 0.60 , CSA cements tend to undergo self-desiccation, as a low water-tocement ratio of $0.30-0.45$ is typically used [23].

The durability of building materials made from CSA cements, as derived from laboratory tests and from field studies, seems to be in general at least comparable to conventional Portland cement-based materials [23], [24], [25], however more data concerning long-term behavior are needed. CSA-based concretes can exhibit a high resistance to freeze-thaw and against chemical attack by seawater, sulfates, chlorides, magnesium and ammonium salts [23], [24], [25], Much of this resistance could be due to the dense pore structures developed by CSA cements. Porosity measurements by mercury intrusion porosimetry have revealed that hydrated CSA cements exhibit mainly pores of a threshold radius below $25 \mathrm{~nm}$ and only a minor content of larger pores forming an interconnected pore network [23] and, leading to high impermeability [25] and . Carbonation depends on the water-to-cement ratio and appears to be more rapid than in Portland cement concretes, leading to 
the decomposition of ettringite, which may cause a moderate strength loss. Despite that, the alkalinity of CSA cements is about $1 \mathrm{pH}$ unit lower than for Portland cements, and the steel reinforcement seems to be protected from corrosion [23]. The low alkalinity also seems to be favorable concerning alkali aggregate reaction [25].

\section{Conclusions}

Compares calcium aluminate cement and calcium sulfoaluminate cement with Portland cement to the two alternative binders explored in this paper in terms of the properties discussed herein, namely composition, energy use, $\mathrm{CO} 2$ emissions, and performance. While there are obvious and substantial differences between these materials, remarkably they all have a period of fluidity to enable mixing and placement and substantial strength gains in the absence of applied heat, enabling use for the same applications. While recent years have shown dramatic improvements in the performance of alternative cementitious binders and an increased understanding of their chemistries, reaction mechanisms and property development, these binders continue to only be used in niche applications and have yet to see widespread use. The primary hindrances to the adoption of alternative binders are the higher costs compared to Portland cement and the prescriptive nature of specifications for binders in concrete. As performance-based specifications become more prevalent, it is likely that the use of alternative binders will increase. Along with increased use will come further research in these systems, including in-depth investigations on reaction kinetics parallel to efforts in Portland cement. Calcium aluminate cements offer rapid strength gain and good durability in high sulfate environments. However, they have suffered a poor reputation because of the loss in strength that occurs over time due to the conversion of metastable hydration products to more dense stable hydration products, increasing the porosity. Recent studies into the combination of calcium aluminate cements with supplementary cementing materials and chemical admixtures have resulted in a lower cost material that effectively eliminates the formation of metastable hydrates, in turn eliminating the problem of conversion. Calcium sulfoaluminate cements are touted for their low $\mathrm{CO} 2$ emissions and energy demand. They also have performance benefits over Portland cement, particularly their rapid strength gain and ability to bind heavy metals. The challenges facing these materials have primarily been the cost of bauxite, lack of understanding of phase formation and property development for materials with varied compositions, and the unknown long-term durability. These challenges are being met through further investigation into using wastes as raw material, thermodynamic modeling of phase formation, and long-term durability characterization.

\section{References}

[1]. U.S. Geological Survey Mineral Commodity Summaries (January 2009

[2]. A. Alcorn Embodied energy and CO2 coefficients for NZ building materials Centre for Building Performance Research Report, Victoria University of Wellington, New Zealand (2003)

[3]. J.S. Damtoft, J. Lukasik, D. Herfort, D. Sorrentino, E.M. GartnerSustainable development and climate change initiativesCem. Concr. Res., 38 (2) (2008), pp. 115-127

[4]. ASTM C 150Standard Specification for Portland Cement ASTM International, West Conshohocken, Pennsylvania (2009)

[5]. ASTM C 1157Standard Performance Specification for Hydraulic CementASTM International, West Conshohocken, Pennsylvania (2009)

[6]. ASTM C 1600Standard Specification for Rapid Hardening Hydraulic CementASTM International, West Conshohocken, Pennsylvania (2009

[7]. EN197-1Cement-Part 1: Composition, Specifications and Conformity Criteria for Common CementsEuropean Committee for Standardization (CEN), Brussels, Belgium(2007)

[8]. EN 206-1Concrete-Part 1: Specification Performance, Production and ConformityEuropean Committee for Standardization (CEN), Brussels, Belgium (2005)

[9]. K.L. Scrivener, A. CapmasCalcium aluminate cementsP.C. Hewlett (Ed.), Lea's Chemistry of Cement and Concrete, Elsevier, Ltd., Oxford, UK (1998), pp. 713-78

[10]. Calcium aluminate cements in construction: a re-assessmentConcrete Society Technical Report TR 46 (1997)

[11]. K.L. ScrivenerHistorical and present day applications of calcium aluminate cementsProceedings of the International Conference on Calcium Aluminate Cements (CAC), Heriot-Watt University, Edinburgh, Scotland, UK, IOM Communications (2001), pp. 3-23

[12]. S.M. Bushnell-WatsonOn the cause of the anomalous setting behaviour with respect to temperature of calcium aluminate cementsCem. Concr. Res., 20 (5) (1990), pp. 677-686

[13]. C. GeorgeIndustrial aluminous cementsP. Barnes (Ed.), Structure and Performance of Cements, Elsevier, London (1983), pp. 415470View Record in Scopus

[14]. Calcium Aluminate Cements: Proceedings of the Centenary Conference, IHS BRE Press, Avignon, France (2008)

[15]. H. Pöllmann, R. Wenda, M. Fylak, J. GöskeCryo-SEM-FEG investigations on calcium aluminate cementsCalcium Aluminate Cements: Proceedings of the Centenary Conference, IHS BRE Press, Avignon, France (2008), pp. 123-137

[16]. J.H. Ideker, Early-age behavior of calcium aluminate cement systems, Ph.D. Thesis, University of Texas, Austin, 2008.

[17]. J.H. Ideker, K.J. Folliard, M.D.A. ThomasEarly-age properties of calcium aluminate cement concrete with rigid cracking and free shrinkage frames: isothermal testingCalcium Aluminate Cements: Proceedings of the Centenary Conference, IHS BRE Press, Avignon, France (2008), pp. 141-157

[18]. S. Lamberet, D. Guinot, E. Lempereur, J. Talley, C. AltField investigations of high performance calcium aluminate mortar for wastewater applicationsCalcium Aluminate Cements: Proceedings of the Centenary Conference, IHS BRE Press, Avignon, France (2008), pp. 269-278 
[19]. M.G. Alexander, A.M. Goyns, C.W. FourieExperiences with a full-scale experimental sewer made with CAC and other cementitious binders in Virginia, South AfricaCalcium Aluminate Cements: Proceedings of the Centenary Conference, IHS BRE Press, Avignon, France (2008), pp. 279-291

[20]. J. Kighelman, K.L. Scrivener, R. ZubriggenKinetics of two types of flooring mortar: PC dominated vs. CAC dominatedCalcium Aluminate Cements: Proceedings of the Centenary Conference, IHS BRE Press, Avignon, France (2008), pp. 567-572

[21]. C. Gosselin, Microstructural development of calcium aluminate cement based systems with and without supplementary cementitious materials, Labratoire des Materiaux de Construction, Ph.D. Thesis, Ecole Polytechnique Federale de Lausanne, 2009

[22]. A. Klein, Calciumaluminosulfate and expansive cements containing same, US Patent No. 3, 155, 526, 1963, 4 pp.

[23]. F.P. Glasser, L. ZhangHigh-performance cement matrices based on calcium sulfoaluminate-belite compositionsCem. Concr. Res., 21 (12) (2001), pp. 1881-1886

[24]. M. Su, W. Kurdowski, F. SorrentinoDevelopment in non-Portlandcements9th International Congress on the Chemistry of Cements, New Delhi, India, vol. I (Nov. 23-28, 1992), pp. 317-354

[25]. M. Su, Y. Wang, L. Zhang, D. LiPreliminary study on the durability of sulfo/ferro-aluminate cements10th International Congress on the Chemistry of Cement, Gothenburg, Sweden (June 2-6, 1997) paper 4iv029, 12 pp 